\title{
Research on the Teaching Operation Mechanism of Intellectual Property Law Course
}

\author{
Shu Luo \\ Law School, Southwest Minzu University, Chengdu, Sichuan, 610041, China \\ luoshu028@163.com
}

Keywords: Intellectual property law; Joint training; Teaching operation mechanism

\begin{abstract}
As an inevitable choice of the postgraduate talent training mode of the intellectual property law, the joint training mode of industry, school and scientific research institution puts forward new requirements for the teaching of intellectual property law courses. In view of the main problems in the teaching of the current intellectual property law course, we need to focus on the development and utilization of teaching resources, multidimensional development of teaching content, transformation of teaching means, the enhancement of practical teaching and so on in the formulation of curriculum teaching plan. At the same time, the teaching supervision and evaluation, the implementation of multiple incentives, and the building of the interactive platform should be taken to ensure the expected effect of the course teaching operation mechanism.
\end{abstract}

\section{Introduction}

Postgraduate education is the main way to train high level intellectual property legal professionals and an important part of the national innovation system. However, intellectual property law postgraduate education can not completely meet the diverse needs of information industry, e-commerce and economic and social development, and the quality of education needs to be improved. How to strengthen the study of course teaching, improve the quality of intellectual property law postgraduate education and realize the goal of talent training has become an important issue.

\section{The Main Problems in the Course Teaching of Intellectual Property Law}

In order to meet the needs of the information age, training applied, compound talents and top notch innovative talents have become an important task and goal of higher education, and the training of legal personnel of the information industry and the legal personnel of intellectual property has become one of the important components. In the current training mode of innovative talents, teaching is generally at the core position, because it is not only the process of optimizing and integrating teaching resources, but also directly related to the quality of personnel training. However, in the process of intellectual property law personnel training, there are still the following outstanding problems:

First, there is a lack of understanding of the positioning of intellectual property law. In the course of teaching and learning, the importance and objectives of law professionals in the information industry and the training of legal personnel in intellectual property law have not been given sufficient attention. On one hand, this objectively reflects the fact that there is a big difference in terms of curriculum arrangement and teaching and operation arrangements due to the non-uniform understanding of the intellectual property law system in the academic circles and on the other hand, it also reflects the current importance of strengthening the training and standardization of law professionals in the information industry.

Second, the training method of the information industry legal personnel and intellectual property law judicial personnel is relatively simple, and this is contradicted with the diverse needs of qualified personnel. The information age has given birth to many new industries and many new jobs. The formed social relations are also more complicated than those in the industrial age and the general business era. Therefore, the voice of practitioners on the diversification of intellectual 
property legal personnel is getting higher and higher. Although employers' vocational training can ease the pressure of employing demand to a certain extent, the connection between talent cultivation and social needs is still very serious. An important reason for this phenomenon is that institutions of higher learning as the important position for personnel training not only lack flexibility in implementing the methods and means of training legal professionals and intellectual property legal personnel in the information industry, but also easily get rid of the real needs, therefore, students are hard to be recognized in practice.

Third, improper design of content in classroom teaching directly affects the quality of teaching. The improper design of teaching content is mainly manifested in the following aspects: First, the teaching content development is too casual. Due to the need of interdisciplinary learning and research, the content of classroom teaching of intellectual property law has a tendency of continuous expansion. Without effective supervision and control, the random development of teaching content may affect the teaching progress. Second, the selection and screening of teaching contents affect the integrity of knowledge structure. Taking the system structure of intellectual property law as an example, various opinions formed actually reflect the differences in perspectives, such as the differences in information dissemination, adjustment of objects and social relations, information activities, subjects and objects, and rights [1]. These will have a direct influence on the choice and arrangement of teaching contents. The limited duration of class needs to choose the teaching content and emphasis, and students will selectively accept it on the basis of this. Ultimately, the actual knowledge structure of the students is extremely incomplete. Third, the design of teaching content that overlooks or seldom considers the characteristics of audiences reduces their motivation to participate in the classroom. In the information era, more materials and resources are provided for teaching. At the same time, more choices are made for students. If the behavior of students is changed and information is not taken into account, rigid teaching contents and teaching methods will affect students' enthusiasm. Fourth, the effective use of cases is not high, and seriously wastes. Case teaching is an important way of cultivating postgraduates of intellectual property law. They are widely used in teaching practice and are welcomed by teachers and students. However, teaching cases are commonly used inefficiently in teaching. Among them, the value of case mining is not conducive to the extension of the students' cases learning, which affects students' ability to give top priority to the situation. The phenomenons, such as old lesson plans, low concern and utilization of new cases, are more prominent. Obviously, how to rationally dispose the teaching content within a limited time has a direct bearing on the improvement of teaching quality, and it has become an urgent issue that needs to be resolved urgently.

Fourth, there is a lack of effective operational mechanism for teaching evaluation of intellectual property law. Evaluation mechanism can promptly reflect the existing problems, but also can provide a reference for the operation of teaching incentives. However, in practice, the evaluation mechanism of the teaching of intellectual property law has not been established or has not operated effectively: on the one hand, teachers do not attach importance to self-evaluation after a certain period of teaching, and are lucky to the existing problems. On the other hand, the lack or lag of the external evaluation mechanism makes it difficult to reflect the problems promptly and facilitate the solution of the problems. Of course, the lack of incentive mechanism weakens the effective operation of the evaluation mechanism to a certain extent.

These issues are inherently related and can be induced for many reasons. One of the important reasons is that there is no macroscopic innovation in personnel training mode according to the actual needs of the information society. On the microcosmic aspect, the design and operation of the intellectual property law curriculum lack norms and guarantees.

\section{The Requirements for the Teaching of Intellectual Property Law Course by the Joint Training Mode of Industry, School and Scientific Research Institution}

The training objective of intellectual property law graduate students is to master the relevant theoretical knowledge in the field of information industry and related legal affairs, have strong ability to solve practical problems, and be able to undertake legal affairs or management work and 
have high-level professional talents with professional accomplishments. In order to achieve the goal of personnel training, we need to re-examine the existing personnel training programs within the framework of the personnel training mode in the light of the current problems in teaching so as to guide the design and operation of specific teaching programs.

The Joint Training Mode of Industry, School and Scientific Research Institution is an Inevitable Choice for the Mode of Cultivating Graduate Students in Intellectual Property Law. According to the "Opinions on Deepening the Reform of Graduate Education" and the "Opinions on Further Promoting the Reform of Postgraduate Cultivation Models for Professional Degrees" in 2013, the goal of the current postgraduate education reform in our country is "to take vocational needs as guidance, take practical ability training as a key point, and take the combination of production and learning as a way, to establish a mode of training graduate students with professional degrees that is suitable for economic and social development and has Chinese characteristics". In terms of cultivating graduate students majoring in intellectual property law, in order to strengthen the cultivation of qualified talents in applied, complex and innovative intellectual property law, it is necessary to establish a reform in the joint training mode of industry, school and scientific research institution. This mode can not only realize the cooperation with enterprises and industries through various flexible ways such as "order-oriented talent training" and "school-district cooperation", but also cultivate the shortage of qualified personnel in a targeted manner. It is also conducive to the rational flow and effective allocation of teachers, and actively explores the reform path of interdisciplinary joint training.

The Influence of The Joint Training Mode of Industry, School and Scientific Research Institution on the Training Program of Intellectual Property Law. To carry out the teaching of intellectual property law courses requires that training programs should be conducted first, that is, the training units need to formulate training programs and make regular revision according to the knowledge and ability structure and professional accomplishment requirements of specialized personnel in the field of intellectual property law and full-time or part-time learning styles. Generally speaking, personnel training program requires "scientific formulation" and "reasonable setting of curriculum system and training links". But after all, it embodies a teaching expectation. It is not difficult to find that the traditional personnel training program emphasizes the advantages of stability, perspectiveness and operability. However, its formation process also suffers from the following deficiencies: First, though the program of personnel training is reviewed and approved by the training units, the scientificity and rationality are actually determined by the main body of the program. Second, the phenomenon of homogeneity of personnel training programs is serious, and the characteristics of economic and social development in the area where the training units are located are not sufficiently reflected in their own advantages. Third, the experts involved in the formulation of training programs or revision work are relatively simple in composition and internalized, and lack the participation of relevant enterprises. Fourth, the phenomenon which pays attention to the teaching theory and despises the practical course is more common.

Obviously, the joint training mode of industry, school and scientific research institution will make up for the lack of existing training programs. By adjusting programs, it will directly guide and influence the teaching of courses. First of all, formulating a training program through the joint training mode of industry, school and scientific research institution of various parties can better reflect the actual needs. Second, the joint training is conducive to the exchange and complementarity of teachers, and it can enrich the content of the subject and guide the training program in reverse. Third, it is conducive to the setting and development of practical courses.

The Requirements for the Teaching of Intellectual Property Law Course by the Joint Training Mode of Industry, School and Scientific Research Institution. The joint training mode of industry, school and scientific research institution not only has a positive impact on talent training programs, but also puts forward new requirements on the teaching of intellectual property law courses. First of all, industry, school and scientific research institution have changed the traditional "learning" or "learning + researching" mode. The injection of "industry" has made curriculum design more targeted and the teaching content needs to be optimized to meet the 
development needs of different types of students. Second, the joint training is not a simple member of the unit stack or patchwork [2]. It can make use of industry, school and scientific research institution to make the various resources of the teaching of intellectual property law give full play to the collection effect and break through the closedness and lag of existing teaching resources to launch the teacher education service product, product + platform, product + platform + brand and more service combinations so as to meet the diverse needs of the market. Thirdly, we should focus on improving the teaching of courses, improving the practice teaching and controlling the teaching and operation links, so as to cultivate the students' innovative spirit and practical ability and enhance students' self-learning and research ability. Fourth, curriculum teaching as a dynamic process needs to establish and improve the evaluation mechanism and incentive mechanism, which are both indispensable and it also needs to consider the particularity of the curriculum itself. Facing new media, the lack of authority of information, the proliferation of information, the fragmentation of information and other issues lead to difficulties in information cognition of college students[3]. These situations also exist in the training of graduate students in intellectual property law. We need to excavate, exploit and utilize resources through profit orientation.

\section{The Main Content of Teaching Operation Mechanism of Intellectual Property Law Course}

In the process of teaching design, teaching implementation and teaching evaluation of intellectual property law courses, the overall planning before teaching, lesson plan design, content adjustment, improvement of teaching methods and practice teaching all need dynamic consideration and design. In general, the teaching operation mechanism of intellectual property law courses includes the following:

Strengthening Teaching Resources Mining, Development, Utilization and Management, and Providing Guarantee for Teaching Mechanism Operation. The information age provides an unprecedented teaching material and resources for teaching. How to mine, exploit and make good use of these resources and enrich the classroom is directly related to the improvement of teaching quality. Under the joint training of industry, school and scientific research institution, the development, utilization and management of intellectual property law teaching resources have the following characteristics: firstly, the intellectual property law teaching resources in the information age are open and the access to resources is not restricted by geographical area, time, etc. However, due to the trend of social media controlling public opinion, it is more important for mass information to guide students to exploit and utilize information in a professional way. Secondly, the joint training of industry, school and scientific research institution makes the intellectual property law teaching resources have strong adaptability, which should adapt to the changes of information technology and information industry, electronic commerce, Internet companies, the instructional resources selection and application in teaching. Thirdly, intellectual property law, as a new discipline, is the result of the legalization of informatization[4]. It should reduce and avoid arbitrariness in teaching and ensure that professionalism is an important guarantee for its promotion and development.

Therefore, in order to ensure the quality of service, preparations for the teaching of intellectual property law before teaching are very important. In this process, we usually go through the following steps: clarifying the target and needs of the audience, preparing teaching materials and collecting data, establishing a content framework according to certain logic, analyzing and processing teaching plan preparation and teaching material contents, making and displaying courseware, and demonstrating courseware. Among them, the focus is on teaching resources collection, and analysis and visualization of teaching content conversion. It is suggested to integrate and recreate the teaching resources by means of software such as Mind Map and Long Picture Frame.

Realizing the Goal that the Teaching Content Changes from One Dimension to Multiple Dimensions, Focusing on Intellectual Property Legal Services Vocational Ability Training. Intellectual property law course itself has strong practicality and comprehensiveness. In order to achieve the goal of personnel training, we must optimize the framework of the curriculum system 
and optimize the teaching content. That is, we need to outline and present its content, characteristics, significance and structure based on the particularity of the course of intellectual property law. However, judging from such aspects as the formulation of current talent cultivation plans, the formation of lesson plans and the implementation of teaching plans, the teaching contents are still mainly decided and led by teachers. Students and substantive departments lack effective participation and the contents of teaching are difficult to meet the actual needs of students. This kind of teaching content has the characteristic of "one degree:. This not only causes that teachers teach knowledge for most of the time in class, but also they are hard to discover students' creative potential.

The author believes that under the jointing training of industry, school and scientific research institution, the teaching of intellectual property law courses urgently needs to change from the one-dimensional operation mode of teaching "teaching content" to the multiple dimensions of "teaching content + relationship". Here the "relationship" includes the following: Firstly, in addition to professional positioning, the choice of teaching content also needs to consider the graduate student's academic interests, knowledge structure, ability and other actual conditions and differences and makes reasonable arrangements. Secondly, the teaching content should also be adjusted according to the needs of enterprises or industries, and when conditions permit, individualized training plans can also be formulated. Thirdly, the content of the course should be linked with the postgraduate's career development education and employment guidance, and actively improve the postgraduate employment and entrepreneurship ability and the intellectual property legal service occupation ability.

Improving Teaching Methods and Promoting Teaching Quality. According to the characteristics of legal education, teaching methods such as case teaching, simulation training or moot court are widely used in practice. However, we can not ignore the problems that exist in these teaching methods in practice. For example, the cases in case teaching are not well-tapped, and it is difficult for the students to give top priority to the situation. The participation of the moot court is not comprehensive enough. In this regard, I proposed the teaching methods of "peeling onions" to improve the existing teaching methods. The so-called teaching method of "peeling onions" teaching method refers to the "form" of onions as the "reality" of intellectual property law and a method of teaching students to "peel onions" to strengthen their ability to analyze and solve problems using the legal system of intellectual property. Practice has proved that this method is feasible and effective, which is not only to make full use of teaching cases, but also greatly mobilize the enthusiasm of students to participate in classroom teaching and also provide inspiration for their extracurricular practice and practice teaching. This method can also effectively implement differentiated teaching and greatly improve teaching quality.

First, we need to determine whether the teaching method of "peeling onions" is applicable. The problem it solves is whether the method will have a good initial assessment of the effectiveness of teaching. Course teaching generally needs to determine the object and teaching time before the end of the previous semester, so it is possible to judge whether or not the teaching method of "peeling onions" is applicable according to the actual object of the course. In particular, to apply this method to case teaching, it is necessary to select the students with certain professional background and knowledge structure. Students who have no relevant background generally can not apply this method in the early stage of teaching.

Second, we need students to recognize "onions". Through structural teaching, students should be helped to form the basic knowledge framework of the law course of intellectual property law. In view of the limited duration, we need to regard the learning content of the legal system of intellectual property as an onion at the initial stage of teaching and strengthen the training of onions identification through the framework of knowledge, logical relations and legal system figures and other forms so that students have an overall grasp of the system and at the same time we should make extension at relevant disciplines and areas according to the needs. Of course, this method can also be used to help students outline the current intellectual property legal personnel training direction and the reality of demand map, in order to facilitate student career planning. 
Third, we should encourage students to carry out the self-study of the legal system of intellectual property with the unique structure of "onions". The application of law pays attention to "taking the facts as the basis and taking the law as the criterion" and in classroom teaching, students often do not pay attention to or ignore the legal provisions of the learning situation. Therefore, it is necessary to strengthen the guidance of students' law study in the early days of teaching. However, many laws of intellectual property and related systems are undoubtedly more challenging for students. Therefore, it is necessary to outline the "onions" framework for students to design and evolve the legal system of intellectual property, and it requires students to carry out various methods to strengthen their study and comparison of specific systems.

Fourth, we use the method of "peeling onions" to activate classroom learning atmosphere and enhance the effective utilization of teaching cases. To mobilize the enthusiasm of students is to stimulate students' interest and participation, and reduce the sense of distance between students and classroom content. Intellectual property law takes encouragement and promoting innovation as the legislative purpose. The applicable area is closely related to the actual life of students. Therefore, we not only need to guide students to be good at using the phenomenon from their own side to exercise their own intellectual property law and related intellectual property system analysis and problem solving skills, but also need to grasp the phenomenon concerned by students to carry out the scene setting for "peeling onions", and let students participate in and study professionally. In this process, we should pay attention to the selection of cases, and the excavation and extension of values, and try our best to minimize the waste.

Strengthening the Practice of Teaching, and Actively Expanding the "Second Lecture Hall". The joint training of industry, school and scientific research institution provides more opportunities for the practical teaching of graduate students in intellectual property law. It can also arouse the enthusiasm and initiative of students actively and cultivate and enhance their self-learning interest and ability. The operation mechanism of practice teaching in law classroom teaching must be constantly optimized so as to effectively improve the quality of subject teaching. [5] Practical teaching sessions will be devoted to expanding "the second lecture hall", and let students become the protagonists, so as to obtain the professional learning test and enhance their abilities.

At present, the approaches taken are mainly as follows: The first one is that students are encouraged to accumulate and collate knowledge in the form of issues such as micro publications and albums around the relevant topics in the intellectual property law. Through the record of learning bit by bit, we can let students know their own learning status and growth process, so as to achieve the students' interest training and guidance. The second one is to encourage students to declare and study research topics of innovative value in the new field of intellectual property law, and summarize their experiences in the scientific research experience. At present, the national level, the provincial level, the school level and the college students' entrepreneurial projects have more opportunities to declare. This can enable students to actively carry out the declaration and research work under the guidance of the tutors and teams in order to explore the potential of graduate students' innovation. The third one is to use the practice platform and practice base of the unit, some students are pushed to participate in the legal work of intellectual property law. At present, in order to enrich the connotation construction of the specialty of intellectual property law, some law schools pay more and more attention to the joint training of talents of intellectual property law. The fourth one is that according to the needs of students, we should encourage students to engage in continuing education and professional training in law related to intellectual property. For example, graduate students with a background in science and engineering are encouraged to take part in examinations and the training for patent agents, and training in intellectual property summer schools. They also study as the exchange students in universities and colleges in Korea and Taiwan, and apply for postgraduates of intellectual property and intellectual property law. The fifth one is the other ways, for example, they deeply discuss the hot cases and topics of intellectual property law through participating in competitions such as moot court competition, computer contest (arts), legal English contest, or participating in clinic education and moot court and so on, so as to achieve the goal of training students. 


\section{The Safeguard Measures of the Operation Mechanism of the Intellectual Property Law Course Teaching}

In order to ensure effective teaching of intellectual property law courses, we also need to establish appropriate safeguards.

Establishing and Perfecting the Quality Control and Evaluation System of the Intellectual Property Law Course Teaching. Under the joint training of Industry, school and scientific research institution, the teaching quality monitoring (including) and evaluation system of intellectual property law courses can be divided into two categories. One is to cultivate internal tracking, monitoring and evaluation and the other is external monitoring and evaluation. The subjects that participating in the operation of intellectual property law teaching are diversified. Therefore, an internal rating mechanism will be formed. This mechanism is mainly based on teachers' self-evaluation and student's curriculum evaluation, supplemented by professional and curriculum evaluation (including personnel training programs, etc.), evaluation of teaching process management, and evaluation of educational resources. Among them, the government policy orientation and the development of information industry will directly affect the evaluation of science and feasibility and rationality of the profession and curriculum, and enterprises directly evaluate the educational resources and teaching process through resources sharing and menu-based customization. As for the external monitoring and evaluation mechanism, the feedback of enterprises on the students' professional application ability, the recognition and evaluation of the research activities carried out by the society around the curriculum and the research results obtained by the society, and the professional evaluation of the evaluation institutions are all important components.

Establishing a Participatory Body for Multiple Incentives. Curriculum teaching requires quality assurance, so it will inevitably need incentive mechanism as a guarantee. However, the incentive mechanism in practice often tends to unilaterally motivate teachers, which is mainly manifested in motivating teachers through the methods of recognizing teachers, adjusting pay and salary, and appraising professional titles. In fact, teaching practice is not only a process of providing teaching service to teachers, but also a process of changing students from ordinary people to professionals, as well as a process of cultivating talents for the diversified needs of enterprises. Therefore, it is necessary to establish a multiple incentive mechanism for the participants to ensure the effective operation of the operation mechanism of intellectual property law courses.

In addition to the teacher's motivation, we also need to focus on the following incentives. First, there is a need to increase students' motivation. The selection of intellectual property law course or major does not represent the successful transition of intellectual property legal personnel, which implies a reasonable elimination mechanism itself. Strengthening incentives will help improve the success rate of talent training and reduce the cost of learning. Second, there is a need to increase incentives for companies and industries involved in co-cultivation. When companies have access to much-needed talent, students also have an active role in the stability of industry, universities and research because of their multiple identities, such as "students, alumni, quality staff or managers". The third one is the incentives for training units or research institutes. On the one hand, through the joint training of industry, school and scientific research institution, we constantly excavate, organize and upgrade their special educational resources and advantageous resources. On the other hand, the effective operation of the course teaching has guaranteed the practice of education services and is therefore easy to gain social recognition. For example, the teaching organization and management mode of "two-way choice and tripartite agreement" formed in practice has realized diversified interests because of post training, double management, curriculum follow-up and ideological training[6].

Setting up an Interactive Information Sharing Platform Jointly Developed by the Institute of Intellectual Property Law. Interactive information sharing platform as an important guarantee for the teaching of the course can promote the development of the joint training of intellectual property law research. Firstly, the platform is an important carrier of information release, which facilitates the participation of multiple subjects in the course construction. Whether it is the 
enterprise's personnel training, legal services, technological innovation and other latest information release, or intellectual property law education teaching forum, quality education and teaching cooperation, intellectual property law and practice, outstanding students' research results, innovative performance and other information, they all can be shared through the platform and achieve a win-win situation. Secondly, the interactive platform can feed back and understand the latest news in time in order to adjust teaching and weaken students' passive situation. Thirdly, as a carrier, the platform can increase the added value of intellectual property for teaching services and can provide the material guarantee for the incentive mechanism through the exercise of the right.

\section{Acknowledgements}

Fund project: Special Fund Project for Intellectual Property Right in Sichuan Province in 2017 (The contract number: 2017-BH-00030); The Online-Open Course Construction Project in Southwest Minzu University(The project number: 2015KCJS28).

\section{References}

[1] Y.Wang and H.Q.Ma: A New Theory on the Construction of Intellectual Property Law System Structure[J], Information Science, 2010(1):24-28.(In Chinese)

[2] B.G.Wang, X.N.Wang and X.M.Liu: The Research on Construction of Effective Teaching Operating Mechanism for the Regional School-Enterprise Group System of Higher Vocational Education[J], Journal of Northeast Agricultural University( Social Science Edition), 2012(12):63-64.(In Chinese)

[3] J.Zhang and H.Wang: Dilemmas of College Students' Information Cognition in New Media Environment[J], Journal of Chongqing University of Posts and Telecommunication(Social Science Edition), 2013(2): 89-93.(In Chinese)

[4] Y.Kuang and W.Ouyang: Status and Proposals of Information Legislation in China[J], Journal of Graduate School of Chinese Academy of Social Sciences, 2007(3):84-89.(In Chinese)

[5] X.Wang: The Operating Mechanism of the Practice Teaching in the Law Class in Colleges and Universities[J], Education and Vocation, 2013(8):152-154.(In Chinese)

[6] C.P.Zhou: Practice of "Two-Way Choice, Three Party Agreement" Practice Teaching Mode[J], Vocational and Technical Education, 2009(11):64-65,69.(In Chinese) 